\title{
Patient Satisfaction in Spine Surgery: A Systematic Review of the Literature
}

\author{
Joshua York Menendez, Nidal Bassam Omar, Gustavo Chagoya, Borna Ethan Tabibian, \\ Galal Ashraf Elsayed, Beverly Claire Walters, Barton Lucius Guthrie, Mark Norman Hadley \\ Department of Neurosurgery, University of Alabama at Birmingham, Birmingham, AL, USA
}

\begin{abstract}
Patient satisfaction reflects the patients' perception of the outcome of care and is being considered for use in future reimbursement schemes. No consensus exists regarding the best instrument to measure patient satisfaction in the field of spine surgery. This systematic review aimed to determine how patient satisfaction for spine surgery has been measured previously and whether a disease-specific, comprehensive instrument to measure patient satisfaction has been established; we also aimed to define the dimensions of care that determine patient satisfaction in spine surgery. A systematic search of three online databases, unpublished sources, and citations was undertaken to identify 156 empirical studies that reported on patient satisfaction in the field of spine surgery. Manuscripts were reviewed in terms of the patient satisfaction instrument used, and the instruments were categorized as per content and method axes. Taxonomy of patient satisfaction with spine surgery identified the major characteristics of providers and medical care that influenced patient satisfaction and acted as a structure to categorically define the dimensions of patient satisfaction in spine surgery. The reviewed studies predominantly used global (108/156) rather than multidimensional (46/156), instruments. Most studies (96.2\%) reported satisfaction with outcome rather than with care, and only $18.5 \%$ of the studies (29/156) utilized a disease-specific instrument. The following seven dimensions of patient status, outcome, and care experience that affected patient satisfaction were identified: pain, function, patient expectations/preference, specific patient health characteristics, caregiver interpersonal manner, efficacy/clinical outcomes, and postoperative care/therapy. Currently, no disease-specific instrument that includes all dimensions of patient satisfaction in spine surgery has been developed. Such a patient satisfaction instrument should be designed, tested for reliability and validity, and widely implemented.
\end{abstract}

Keywords: Patient satisfaction; Patient reported outcome measures; Evidence-based medicine

\section{Introduction}

Patient-reported outcomes are increasingly recognized as meaningful and valid measures of successful care. This is in contrast to traditional surgeon-centered outcome pa- rameters, including morbidity, mortality, complications, and postoperative imaging findings. Patient satisfaction is a type of patient-reported outcome different from reports of health, disability, and quality of life. Patient satisfaction is a measurement that reflects the patients' perception of

Received Jan 27, 2019; Accepted Feb 25, 2019

Corresponding author: Nidal Bassam Omar

Division of Neurosurgery, University of Alabama at Birmingham, 510 20th Street South, FOT 1062

Birmingham, AL 35294-3410, USA

Tel: +1-205-939-9653, Fax: +1-205-939-9972, E-mail: nidalomar@uabmc.edu 
outcome of care and has been considered for use in future reimbursement schemes. Contrary to intuition, satisfaction does not depend only on conventional measures of surgical outcomes. There is a complex interplay that depends on preoperative factors, the interpersonal relationship between the patient and the physician, nurses, and other hospital staff, and these other more traditionally measured outcomes that determine patient satisfaction. High satisfaction increases the likelihood of the patient for pursuing further medical care, promotes patient compliance, and has been linked to a decreased incidence of malpractice suits.

No consensus on patient satisfaction instruments exists in the field of spine surgery. A multidimensional, diseasespecific patient satisfaction instrument could guide changes in surgical practice for quality improvement.

This review aimed to establish how patient satisfaction with spine surgery has been previously measured; determine whether a disease-specific, comprehensive instrument to measure patient satisfaction has been developed or identified; and define the dimensions of care that determine patient satisfaction in spine surgery.

\section{Search Strategy and Study Inclusion}

In September of 2014, MEDLINE, the Cochrane Library, and CINAHL were systematically searched by the study authors for "patient satisfaction," "spine," and "surgery"; "patient expectations," "spine," and "surgery"; "physicianpatient relationship," "spine," and "surgery"; "doctorpatient relationship," "spine," and "surgery"; and "patient preference," "spine," and "surgery"; this search yielded 215 unique publications. Only published, English-language articles were considered. No limitations were placed regarding the publication date. Titles and abstracts of all 215 publications were examined, and the studies were included if they were empirical, reported measurement of patient satisfaction, and referred to spine surgery. Publications were excluded if they were reviews, if they did not measure patient satisfaction, or if they did not involve spine surgery. If the abstract and title were unclear, the full texts were reviewed to decide regarding the inclusion or exclusion of the study. Using these criteria, 87 published articles were excluded, yielding 128 publications that were considered appropriate for further detailed examination. All full-length manuscripts were evaluated, and an additional 15 manuscripts were excluded because they did not

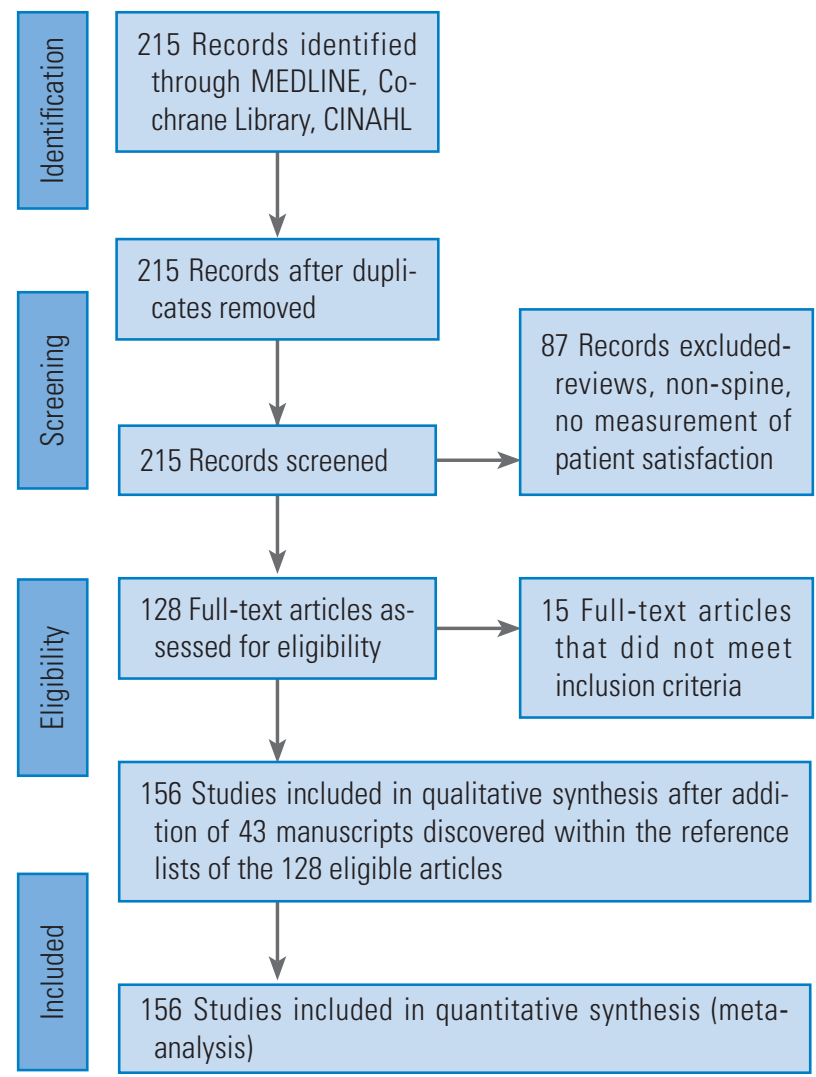

Fig. 1. Flow chart for selection of studies.

meet the inclusion criteria, leaving 113 manuscripts. The reference lists in all papers were reviewed, and an additional 43 manuscripts that fulfilled the inclusion criteria were discovered. In all, 156 empirical studies that measured patient satisfaction in spine surgery were included (Fig. 1).

Spine surgery was defined to include any invasive procedure of the spine. Surgical indications included degenerative spine, trauma, neoplasm, pain, and function. Patient satisfaction was defined as any attempt of a study or gather evaluations or "affective responses" regarding a patient's health care experience $[1,2]$.

All the articles were critically read by the authors of this review, and data were categorically extracted. The categories included study type (retrospective, prospective, blinded, and controlled), disease process (degenerative spine, trauma, pain, functional, and neoplasm), procedures performed (decompression, fusion, spinal cord stimulator, and pain pump), number of surgeons, follow-up duration, country of residence of the participants, number of participants, outcome measurements, patient satisfaction instrument used, delivery format (self- or interviewer- 
administered), validity of the instrument, and findings of the study.

Using these data, the characteristics of the patient satisfaction instruments used in each study were classified using the criteria described by Hudak and Wright [1]. These authors note that the characteristics of patient satisfaction instruments fall into the following two major categories: content and methods. Content describes the focus of the measurement tool, and methods describe the measurement technique used by the instrument. Both the content and methods categories have four axes. The axes within the content category are as follows: global versus multidimensional questions, satisfaction with care versus satisfaction with outcome, generic universal questions versus disease-specific questions, and direct versus indirect questions. The four method axes are divided into factual versus affective questions, open- versus closed-ended questions, self- verses interviewer-administered instruments, and type of response format.

In reviewing the findings of each study, taxonomy of patient satisfaction with spine surgery was developed that identified the major characteristics of providers and medical care that influenced patient satisfaction. In the pioneering work for the clarification of the dimensions of patient satisfaction with medical care, Ware et al. [3] formed taxonomy from reviewed studies to form the basis for the development of the dimensions of care that affected patient satisfaction. In a similar manner, our taxonomy acted as a structure to categorically define the dimensions of patient satisfaction in spine surgery.

\section{Current Measurement Instruments}

Patient satisfaction measurement instruments used in the 156 manuscripts were categorized using the model developed by Hudak and Wright [1] for patient satisfaction instrument content and methods (Fig. 1). In the present study, the content of the instruments featured mostly global (68.8\%) rather than multidimensional (29.3\%) surveys that measured patient satisfaction with outcome (96.2\%) rather than with care (1.9\%). Most instruments contained generic satisfaction questions (79.6\%) rather than disease-specific questions (18.5\%), and more instruments used a direct $(82.2 \%)$ rather than an indirect (15.3\%) approach.

The methods of the instruments employed affective (79.6\%) rather than factual (12.1\%) questions and pre- ferred closed-ended questions (89.2\%) over open-ended questions (7.6\%). No study relied solely on open-ended questions. Most instruments were self-administered (81.5\%), and few were administered by the interviewer (10.8\%). The most common question format was a Likert format $(79.0 \%)$ with a varying number of gradations, although $11.5 \%$ used only binary (yes/no) responses, and $3.8 \%$ used a satisfaction Visual Analog Scale (VAS).

The most commonly used multidimensional patient satisfaction instrument was the Brigham Spinal Stenosis Questionnaire (11/156), also called the Swiss Spinal Stenosis Questionnaire and the Zurich Spinal Stenosis Questionnaire 4 . The second most common instruments were the 36-item Short-Form Health Survey (SF-36) and the North American Spinal Society (NASS) Low Back Outcome $[4,5]$.

\section{Dimensions of Patient Satisfaction}

Of the 156 papers included in this study, 81 did not include an analysis that contributed to the determination of the dimensions of care. In these 81 papers, the patient satisfaction instrument was strictly used either to report the satisfaction level or compare satisfaction between the procedures without analyzing which aspects of care contributed to this satisfaction. Using the remaining $75 \mathrm{pa}-$ pers, taxonomy of the following factors that affect patient satisfaction was constructed: pain/sensibility; physical function; patient characteristics; complications or adverse events; radiographic results; expectations; preference; information provided by the surgeon; disability; postoperative care, physical therapy, or nursing; self-image, wound appearance, or general health; surgeon characteristics; spinal levels treated; preoperative surgeon prediction of satisfaction; and spinal disease process. Using this taxonomy, the following seven dimensions of patient status, outcome, and care experience that influenced patient satisfaction were identified: pain, function, patient expectations or preference, specific patient health characteristics, caregiver interpersonal manner, efficacy or clinical outcomes, and postoperative care or therapy.

\section{Pain}

Total 37 studies evaluated patient satisfaction in terms of pain or sensibility [6,7-41]. These studies used various instruments, including the VAS, American Pain Society 
Questionnaire, Japanese Orthopedic Association Score for Back Pain, nonspecific questionnaires, or simple global satisfaction questions. Some studies linked satisfaction to preoperative pain scores; others reported satisfaction based on the change in pain after the surgery; others found an association between postoperative pain independent of preoperative pain, while still others found no association between satisfaction and pain.

Bouras et al. [13] found that satisfied patients reported a mean postoperative VAS pain score of 3.0, lower compared to 6.0 recorded at baseline. This was favorable compared to the responses of dissatisfied patients who had a mean postoperative score of 8.53 , lower than that $(0.47)$ at baseline. This relationship has been reported in several other studies that demonstrate either a correlation between an absolute lower score on the VAS, Numerical Rating Scale, or other pain scale and higher satisfaction rates $[14,29,40]$ or, more commonly, a decrease in the postoperative pain a higher rate of satisfaction $[16,17,19,22,25,38,39,41]$. However, some reports show higher scores on the VAS or a similar pain scale that correlate to a lower satisfaction rate $[10,24,26,28,34,37,42]$ or lack of pain reduction leading to lower satisfaction [25]. Emami et al. [42] and Kim et al. [24] have reported higher rates of pain and lower rates of global satisfaction in patients with a radiographically apparent etiology of pain, such as pseudarthrosis.

The most commonly utilized multidimensional instrument to determine patient satisfaction with spine surgery is the Brigham Spinal Stenosis Questionnaire that utilizes the pain domain. Stucki et al. [36] validated this instrument in 1995 and in the same study, found that the severity of symptoms documented in the pain domain was a controlling factor in overall satisfaction. This finding has been corroborated by two other studies [15,21]. Further use of this same instrument showed a stronger correlation of symptom relief and patient satisfaction [6].

Both, the duration and location of painful symptoms in the postoperative period affect the satisfaction rates. Patients with preoperative back pain rather than radicular leg pain have lower rates of satisfaction $[7,20]$. Ohnmeiss and Rashbaum [31] found that satisfaction decreased with increasing duration of postoperative back pain.

Comparisons between intravenous, oral and intravenous, and epidural regimens for postoperative analgesia have been studied. Satisfaction levels were greater with epidural analgesia following long segment fusion for cor- rection of adolescent idiopathic scoliosis [11,12]; however, no difference was noted between the effects of oral and intravenous regimens [32].

North et al. [30] studied failed back syndrome and found lower rates of pain and higher satisfaction in patients undergoing spinal cord stimulation than in those undergoing revision decompression.

\section{Function}

Improvement in functional capacity naturally has a positive effect on satisfaction; this association is also reported in the literature; 30 of the studies we reviewed reported that measurement of the functional outcome is a controlling factor in overall patient satisfaction $[6,10,13$ $18,20,21,23,26-29,34-37,39,40,43-51]$. The most common outcome measures reported were the SF-36 Physical Component Summary, the Oswestry Disability Index (ODI), and various iterations of the Scoliosis Research Society questionnaire.

Improvement in the functional outcome scores lead to higher reported rates of satisfaction in many studies [6,13$15,17,29,35,36,40,43,45,48,49,51]$; however, this effect was found to be short-lived [23] or inferior to the effect of other factors, such as pain $[18,42]$. The concomitant effect of decreased functional capacity or a small improvement in the postoperative functional capacity correlated to lower rates of satisfaction [26-28,34].

The capacities that were most commonly correlated with satisfaction rates were ambulation and mobility. The evaluation of ambulation for this purpose can either be objective (e.g., a directly observed walking distance) [44], data derived from an interview [21], or a patient's subjective feelings and/or perceptions about his/her ability to ambulate [39]. In all instances, improvement in ambulation was correlated with a higher degree of global satisfaction with the procedure. Research has also showed the inverse of this to be true $[34,37]$.

Preoperative functional capacity is shown to be inversely related to the reported level of satisfaction with the procedure $[20,46,50]$. The exception to this association was in patients with myelopathy. Anand and Regan [43] prospectively studied a video-assisted thoracoscopic surgery approach to thoracic disk herniations and found higher levels of satisfaction in patients who were more impaired preoperatively (myelopathic), as measured using the ODI. These patients who were functionally incapacitated by the 
thoracic disk herniation had a larger functional improvement postoperatively, and this appears to be the controlling factor in the functional domain.

\section{Patient expectations and preference}

Patients' personal value systems and expectations considerably impact their ultimate satisfaction. Twelve papers found an association between individual expectations and patient satisfaction [28,33,44,46,49,51-57].

Contradictory results have been reported regarding the effect of preoperative expectations, with some studies reporting that higher expectations are associated with higher satisfaction levels [28,44,52-55], while others reporting the opposite [51,56]. Iversen et al. [46] and Rönnberg et al. [49] both found that increased expectations with regard to postoperative pain control lead to lower global satisfaction, while increased expectations with regard to postoperative function lead to higher satisfaction rates. High scores on the SF-36 Mental Component Summary in the preoperative period were specifically linked to higher satisfaction rates in two studies $[52,54]$.

Toyone et al. [57] studied patient satisfaction after lumbar laminectomy or lumbar discectomy using the NASS instrument and found a difference in the satisfaction and expectation levels between the two disease processes and their specific procedures. Patients undergoing lumbar discectomy with high expectations of improvement were more satisfied with the surgery than those undergoing lumbar laminectomy for spinal stenosis who had high expectations of improvement and were generally less satisfied with the surgery.

Shabat et al. [33] studied sex-based differences in patient satisfaction after lumbar decompression in elderly patients to find that men and women possess different expectations of success in spinal surgery; $51 \%$ women versus $66 \%$ men had expectations of a positive outcome preoperatively.

\section{Specific patient health characteristics}

Patient-specific health characteristics are the traits of individual patients that cannot be modified in the short preoperative period; however, these characteristics may have a considerable impact on the perceived benefits that a patient derives from an intervention. Total 25 studies involved patient-specific health characteristics
$[9,10,18,20,26,31,33-35,44,46,49,51,57-68]$. The most common characteristics that were identified were specific medical comorbidities, smoking status, etiology of spinal pathology, sex, and financial variables.

Several studies supported the notion that patients with multiple medical comorbidities had poorer satisfaction with spine surgery [20,51]. Comorbidities that were specifically implicated were cardiac disease [63], osteoarthritis $[9,33]$, type II diabetes mellitus, peripheral vascular disease [9], smoking [60,67], and obesity [64]. Depression was the medical problem that was most commonly linked to low satisfaction rates $[9,34,49,63]$.

In addition, demographic data affected the satisfaction rates. Age was commonly investigated as a characteristic that could affect satisfaction; however, three studies showed that there was no significant difference in the satisfaction reported by different, non-pediatric, age groups $[18,31,35]$. The literature concerning the sex-based differences in the satisfaction rates yields conflicting data. Shabat et al. [33] and Gepstein et al. [44] found that men generally reported higher rates of satisfaction as compared to women; however, Iversen et al. [46] and North et al. [65] report that women report higher satisfaction rates. Ohnmeiss and Rashbaum [31] found no sex-based differences in the satisfaction rates.

Gepstein et al. [44] and Katz et al. [63] found that higher levels of income correlated to a higher degree of satisfaction with the surgical outcome. Skolasky et al. [35] used the Cervical Spine Outcome Questionnaire with advanced modeling to study patient satisfaction after anterior cervical discectomy and fusion and found that it correlated with socioeconomic factors, including workmen's compensation and unemployment insurance; however, they did not state how these circumstances altered satisfaction [69].

The etiology of spinal complaints and characteristics of presenting symptoms have been implicated in several studies. The Maine Lumbar Spine Study found that patients who presented with unilateral leg pain and those with symptoms for $<1$ year preoperatively reported higher satisfaction rates than other patients [58]. Revision surgery was associated with lower satisfaction in two studies $[26,60]$. Slosar et al. [68] found that patients who presented with discogenic pain had lower satisfaction with lumbar arthrodesis than those who underwent the same procedure of pseudarthrosis or spondylolisthesis. Heyrani et al. [61] reported on the use of an interspinous implant 
and recorded higher rates of satisfaction in patients with a grade I spondylolisthesis than in those without a sagittal deformity.

\section{Caregiver interpersonal manner}

Caregiver interpersonal manner is included in the care portion of the care/outcome axis of patient satisfaction; very few studies have measured this parameter. Although only three studies directly examined the satisfaction on the care axis $[49,70,71]$, five studies have shown a relationship between the counseling or bedside manner of the treating physician and patient-reported satisfaction $[21,26,49,53,63]$.

The manner in which physicians counsel a patient in the preoperative clinic setting is the factor most commonly associated with satisfaction in the sphere of physician interpersonal manner. Multiple studies have related the satisfaction with outcome to preoperative counseling, especially with regard to pain $[26,49]$. In contrast, de Groot et al. [53] investigated this relationship and found no correlation. On the basis of two studies, Katz et al. [21,63] reported that a patient's subjective assessment of their general health in the preoperative setting was the most significant metric in predicting postoperative satisfaction and pain outcomes.

\section{Treatment efficacy and clinical outcomes}

Of the 75 manuscripts that analyzed the pertinent domains of patient satisfaction, 12 analyzed the treatment efficacy and clinical outcomes [10,42,47,71-79]. There was no consistent correlation between the achievement of the radiographic goal and achievement of satisfaction. In studies regarding dorsal correction of scoliosis [10], lumbar interbody fusion [79], and postoperative pseudarthrosis [74], no correlation was found between the fusion status on follow-up radiographs and patient satisfaction. Newton et al. [47] found that following short segment fusions for scoliosis, patients were more satisfied if they had increased flexibility on these short segment fusions than on long segment fusions. Kaptain et al. [73] studied kyphosis after cervical laminectomy and found no correlation between satisfaction and radiologic outcomes, including kyphosis.

Multiple studies have looked at perioperative complications and how they affect satisfaction. Universally, the presence of complications has decreased reported satisfaction $[42,71,72,75,77]$. Mannion et al. [76] prospectively studied surgery on adults with degenerative spine disease and found a strong correlation between treatment effectiveness and patient satisfaction (Spearman Rho $=0.64$ ). However, there were some inconsistencies; of the "very dissatisfied" patients, $20 \%$ reported that the procedure "helped" or "helped a lot." In the group of "very satisfied" patients, $9 \%$ stated that the operation "helped only a little," and 5\% stated that it "had not helped" or "made things worse." This may be explained by the satisfaction with other parts of the experience rather than with the clinical outcome.

\section{Postoperative care and therapy}

Of the 75 manuscripts that analyzed patient satisfaction, four analyzed the postoperative care and therapy using varying methods and instruments $[46,70,80,81]$.

Iversen et al. [46] prospectively studied patient satisfaction using a Likert-like questionnaire in patients with lumbar spinal stenosis undergoing decompression or fusion. They reported that patients receiving postoperative physical therapy or home nursing care were more satisfied with their outcomes. Johansson et al. [70] studied patient satisfaction after lumbar discectomy comparing clinicversus home-based physiotherapy. Patients were more satisfied with clinic-based therapy than with home therapy. Kjelby-Wendt and Styf [80] compared two types of home physiotherapy using an undefined instrument for patients undergoing lumbar discectomy and found that patients were more satisfied after early mobilization and increased postoperative activity. While there is no consistent measurement instrument or method of study among these investigations, there is an obvious association between postoperative physical therapy and activity and overall satisfaction with spine surgery.

Lorish et al. [81] studied the correlation between patient satisfaction and length of hospital stay after lumbar microdiscectomy using a Likert scale. They did not find a difference in the satisfaction between patients discharged on postoperative day one and those discharged on postoperative day 2 . This is the only spine surgery study that evaluated patient satisfaction related to the length of hospital stay. 


\section{Discussion}

Recently, there has been an increased interest in the measurement of patient satisfaction; patient-reported outcomes are increasingly recognized as valid markers for therapeutic efficacy, with discussions concerning the use of patient satisfaction in the determination of reimbursement schedules.

In addition to the issue of financial implications, there are patient-care issues. Patients who are more satisfied with their medical care are known to have better longterm outcomes $[82,83]$. Satisfied patients are more compliant with treatment regimens, develop lasting relationships with their medical providers, and are more apt to present promptly with new signs and symptoms. The converse is even more strongly evident, with dissatisfied patients exhibiting a tendency toward non-compliance and delayed presentation [1].

There are unique characteristics of the manner in which spine pathology presents and is treated that necessitates accurate measurement of patient satisfaction. Subjective symptoms rather than objective signs are the characteristics of varying spinal pathologies. Patients with the same degree of stenosis can have drastically different presentations in terms of pain and dysfunction. In a similar manner, patients can have very similar operations with regard to the extent of decompression and have very different responses in terms of pain control. The difference between these patients is very difficult to quantify. An acceptable patient satisfaction measure would allow quantification of the postoperative subjective improvement and allow a comparison across patients and studies.

As the preceding systematic review shows, the current state of the measurement of patient satisfaction is non-standardized and in most cases, there is no attempt to understand what drives patients' satisfaction or dissatisfaction. There is no widely adopted, disease-specific instrument that accounts for the different domains that consistently and directly affect satisfaction in spinal surgery.

Such an instrument would be disease-specific and would measure satisfaction in a multidimensional manner that includes all seven domains identified as affecting satisfaction scores. Such an instrument would assess satisfaction with both outcome and care in a direct manner. It would use closed-ended, affective questions with a Likertlike or binary response format and would be administered either via the interview or questionnaire method.

These dimensions of care have been defined using the literature review technique. While this approach elucidates dimensions of care, there is no means of applying value to each dimension appropriately and understanding if there are collinear dimensions that will cancel each other out. It is highly unlikely that each dimensions of patient satisfaction is of equal value in determining overall satisfaction. The designing of an instrument that uses these dimensions and psychometric testing would enable the establishment of appropriate values and collinear variables to provide utility to such a model.

\section{Conclusions}

Patient satisfaction is increasingly being recognized as an important and distinct patient-reported outcome measure. Other outcome measures are consistently measured and reported; however, patient satisfaction is inconsistently measured and haphazardly reported. There is a need to develop an instrument to measure patient satisfaction in the field of spine surgery; wide use of such as instrument would help in determining the efficacy of surgical intervention for spinal pathology.

\section{Conflict of Interest}

No potential conflict of interest relevant to this article was reported.

\section{References}

1. Hudak PL, Wright JG. The characteristics of patient satisfaction measures. Spine (Phila Pa 1976) 2000;25:3167-77.

2. Linder-Pelz SU. Toward a theory of patient satisfaction. Soc Sci Med 1982;16:577-82.

3. Ware JE Jr, Davies-Avery A, Stewart AL. The measurement and meaning of patient satisfaction. Health Med Care Serv Rev 1978;1:1,3-15.

4. Copay AG, Glassman SD, Subach BR, Berven S, Schuler TC, Carreon LY. Minimum clinically important difference in lumbar spine surgery patients: a choice of methods using the Oswestry Disability Index, Medical Outcomes Study questionnaire Short Form 36, and pain scales. Spine J 2008;8:968-74.

5. Guilfoyle MR, Seeley H, Laing RJ. The Short Form 
36 health survey in spine disease: validation against condition-specific measures. Br J Neurosurg 2009;23:401-5.

6. Stucki G, Daltroy L, Liang MH, Lipson SJ, Fossel AH, Katz JN. Measurement properties of a self-administered outcome measure in lumbar spinal stenosis. Spine (Phila Pa 1976) 1996;21:796-803.

7. Anand N, Hamilton JF, Perri B, Miraliakbar H, Goldstein T. Cantilever TLIF with structural allograft and RhBMP2 for correction and maintenance of segmental sagittal lordosis: long-term clinical, radiographic, and functional outcome. Spine (Phila Pa 1976) 2006;31:E748-53.

8. Andersen T, Christensen FB, Hoy KW, et al. The predictive value of pain drawings in lumbar spinal fusion surgery. Spine J 2010;10:372-9.

9. Arinzon Z, Adunsky A, Fidelman Z, Gepstein R. Outcomes of decompression surgery for lumbar spinal stenosis in elderly diabetic patients. Eur Spine J 2004;13:32-7.

10. Berven SH, Deviren V, Smith JA, Emami A, Hu SS, Bradford DS. Management of fixed sagittal plane deformity: results of the transpedicular wedge resection osteotomy. Spine (Phila Pa 1976) 2001;26:2036-43.

11. Blumenthal S, Borgeat A, Nadig M, Min K. Postoperative analgesia after anterior correction of thoracic scoliosis: a prospective randomized study comparing continuous double epidural catheter technique with intravenous morphine. Spine (Phila Pa 1976) 2006;31:1646-51.

12. Blumenthal S, Min K, Nadig M, Borgeat A. Double epidural catheter with ropivacaine versus intravenous morphine: a comparison for postoperative analgesia after scoliosis correction surgery. Anesthesiology 2005;102:175-80.

13. Bouras T, Stranjalis G, Loufardaki M, Sourtzis I, Stavrinou LC, Sakas DE. Predictors of long-term outcome in an elderly group after laminectomy for lumbar stenosis. J Neurosurg Spine 2010;13:329-34.

14. Carreon LY, Sanders JO, Diab M, Sturm PF, Sucato DJ; Spinal Deformity Study Group. Patient satisfaction after surgical correction of adolescent idiopathic scoliosis. Spine (Phila Pa 1976) 2011;36:965-8.

15. Fokter SK, Yerby SA. Patient-based outcomes for the operative treatment of degenerative lumbar spinal stenosis. Eur Spine J 2006;15:1661-9.

16. Fujimori T, Iwasaki M, Okuda S, et al. Patient satis- faction with surgery for cervical myelopathy due to ossification of the posterior longitudinal ligament. J Neurosurg Spine 2011;14:726-33.

17. Glassman SD, Hamill CL, Bridwell KH, Schwab FJ, Dimar JR, Lowe TG. The impact of perioperative complications on clinical outcome in adult deformity surgery. Spine (Phila Pa 1976) 2007;32:2764-70.

18. Hansraj KK, Cammisa FP Jr, O'Leary PF, et al. Decompressive surgery for typical lumbar spinal stenosis. Clin Orthop Relat Res 2001;(384):10-7.

19. Hessler C, Boysen K, Regelsberger J, Vettorazzi E, Winkler D, Westphal M. Patient satisfaction after anterior cervical discectomy and fusion is primarily driven by relieving pain. Clin J Pain 2012;28:398-403.

20. Katz JN, Lipson SJ, Brick GW, et al. Clinical correlates of patient satisfaction after laminectomy for degenerative lumbar spinal stenosis. Spine (Phila Pa 1976) 1995;20:1155-60.

21. Katz JN, Lipson SJ, Chang LC, Levine SA, Fossel AH, Liang MH. Seven- to 10-year outcome of decompressive surgery for degenerative lumbar spinal stenosis. Spine (Phila Pa 1976) 1996;21:92-8.

22. Khan SN, Hofer MA, Gupta MC. Lumbar degenerative scoliosis: outcomes of combined anterior and posterior pelvis surgery with minimum 2-year follow-up. Orthopedics 2009;32.

23. Kikuike K, Miyamoto K, Hosoe H, Shimizu K. Onestaged combined cervical and lumbar decompression for patients with tandem spinal stenosis on cervical and lumbar spine: analyses of clinical outcomes with minimum 3 years follow-up. J Spinal Disord Tech 2009;22:593-601.

24. Kim YJ, Bridwell KH, Lenke LG, Rhim S, Cheh G. Pseudarthrosis in long adult spinal deformity instrumentation and fusion to the sacrum: prevalence and risk factor analysis of 144 cases. Spine (Phila Pa 1976) 2006;31:2329-36.

25. Kleinstueck FS, Fekete T, Jeszenszky D, et al. The outcome of decompression surgery for lumbar herniated disc is influenced by the level of concomitant preoperative low back pain. Eur Spine J 2011;20:1166-73.

26. Kong CB, Jeon DW, Chang BS, Lee JH, Suk KS, Park JB. Outcome of spinal fusion for lumbar degenerative disease: a cross-sectional study in Korea. Spine (Phila Pa 1976) 2010;35:1489-94.

27. L'Heureux EA Jr, Perra JH, Pinto MR, Smith MD, Denis F, Lonstein JE. Functional outcome analysis 
including preoperative and postoperative SF-36 for surgically treated adult isthmic spondylolisthesis. Spine (Phila Pa 1976) 2003;28:1269-74.

28. Licina P, Johnston M, Ewing L, Pearcy M. Patient expectations, outcomes and satisfaction: related, relevant or redundant? Evid Based Spine Care J 2012;3:13-9.

29. Neo M, Fujibayashi S, Takemoto M, Nakamura T. Clinical results of and patient satisfaction with cervical laminoplasty for considerable cord compression with only slight myelopathy. Eur Spine J 2012;21:3406.

30. North RB, Kidd DH, Farrokhi F, Piantadosi SA. Spinal cord stimulation versus repeated lumbosacral spine surgery for chronic pain: a randomized, controlled trial. Neurosurgery 2005;56:98-106.

31. Ohnmeiss DD, Rashbaum RF. Patient satisfaction with spinal cord stimulation for predominant complaints of chronic, intractable low back pain. Spine J 2001;1:358-63.

32. Rajpal S, Gordon DB, Pellino TA, et al. Comparison of perioperative oral multimodal analgesia versus IV PCA for spine surgery. J Spinal Disord Tech 2010;23:139-45.

33. Shabat S, Folman Y, Arinzon Z, Adunsky A, Catz A, Gepstein R. Gender differences as an influence on patients' satisfaction rates in spinal surgery of elderly patients. Eur Spine J 2005;14:1027-32.

34. Sinikallio S, Aalto T, Airaksinen O, et al. Lumbar spinal stenosis patients are satisfied with short-term results of surgery: younger age, symptom severity, disability and depression decrease satisfaction. Disabil Rehabil 2007;29:537-44.

35. Skolasky RL, Albert TJ, Vaccaro AR, Riley LH 3rd. Patient satisfaction in the cervical spine research society outcomes study: relationship to improved clinical outcome. Spine J 2009;9:232-9.

36. Stucki G, Liang MH, Fossel AH, Katz JN. Relative responsiveness of condition-specific and generic health status measures in degenerative lumbar spinal stenosis. J Clin Epidemiol 1995;48:1369-78.

37. Tuite GF, Stern JD, Doran SE, et al. Outcome after laminectomy for lumbar spinal stenosis: part I: clinical correlations. J Neurosurg 1994;81:699-706.

38. Willems PC, Elmans L, Anderson PG, van der Schaaf DB, de Kleuver M. Provocative discography and lumbar fusion: is preoperative assessment of adjacent discs useful? Spine (Phila Pa 1976) 2007;32:1094-9.

39. Yamashita K, Hayashi J, Ohzono K, Hiroshima K. Correlation of patient satisfaction with symptom severity and walking ability after surgical treatment for degenerative lumbar spinal stenosis. Spine (Phila Pa 1976) 2003;28:2477-81.

40. Yamashita K, Ohzono K, Hiroshima K. Patient satisfaction as an outcome measure after surgical treatment for lumbar spinal stenosis: testing the validity and discriminative ability in terms of symptoms and functional status. Spine (Phila Pa 1976) 2006;31:2602-8.

41. Zanoli G, Stromqvist B, Jonsson B. Visual analog scales for interpretation of back and leg pain intensity in patients operated for degenerative lumbar spine disorders. Spine (Phila Pa 1976) 2001;26:2375-80.

42. Emami A, Deviren V, Berven S, Smith JA, Hu SS, Bradford DS. Outcome and complications of long fusions to the sacrum in adult spine deformity: luquegalveston, combined iliac and sacral screws, and sacral fixation. Spine (Phila Pa 1976) 2002;27:776-86.

43. Anand N, Regan JJ. Video-assisted thoracoscopic surgery for thoracic disc disease: classification and outcome study of 100 consecutive cases with a 2-year minimum follow-up period. Spine (Phila Pa 1976) 2002;27:871-9.

44. Gepstein R, Arinzon Z, Adunsky A, Folman Y. Decompression surgery for lumbar spinal stenosis in the elderly: preoperative expectations and postoperative satisfaction. Spinal Cord 2006;44:427-31.

45. Godil SS, Parker SL, Zuckerman SL, et al. Determining the quality and effectiveness of surgical spine care: patient satisfaction is not a valid proxy. Spine J 2013;13:1006-12.

46. Iversen MD, Daltroy LH, Fossel AH, Katz JN. The prognostic importance of patient pre-operative expectations of surgery for lumbar spinal stenosis. Patient Educ Couns 1998;34:169-78.

47. Newton PO, Upasani VV, Bastrom TP, Marks MC. The deformity-flexibility quotient predicts both patient satisfaction and surgeon preference in the treatment of Lenke 1B or 1C curves for adolescent idiopathic scoliosis. Spine (Phila Pa 1976) 2009;34:10329.

48. Pratt RK, Fairbank JC, Virr A. The reliability of the Shuttle Walking Test, the Swiss Spinal Stenosis Questionnaire, the Oxford Spinal Stenosis Score, and 
the Oswestry Disability Index in the assessment of patients with lumbar spinal stenosis. Spine (Phila $\mathrm{Pa}$ 1976) 2002;27:84-91.

49. Ronnberg K, Lind B, Zoega B, Halldin K, Gellerstedt M, Brisby H. Patients' satisfaction with provided care/information and expectations on clinical outcome after lumbar disc herniation surgery. Spine (Phila Pa 1976) 2007;32:256-61.

50. Siepe CJ, Tepass A, Hitzl W, et al. Dynamics of improvement following total lumbar disc replacement: is the outcome predictable? Spine (Phila Pa 1976) 2009;34:2579-86.

51. Soroceanu A, Ching A, Abdu W, McGuire K. Relationship between preoperative expectations, satisfaction, and functional outcomes in patients undergoing lumbar and cervical spine surgery: a multicenter study. Spine (Phila Pa 1976) 2012;37:E103-8.

52. Carr FA, Healy KM, Villavicencio AT, et al. Effect on clinical outcomes of patient pain expectancies and preoperative Mental Component Summary scores from the 36-item Short Form Health Survey following anterior cervical discectomy and fusion. J Neurosurg Spine 2011;15:486-90.

53. De Groot KI, Boeke S, Passchier J. Preoperative expectations of pain and recovery in relation to postoperative disappointment in patients undergoing lumbar surgery. Med Care 1999;37:149-56.

54. Derby R, Lettice JJ, Kula TA, Lee SH, Seo KS, Kim BJ. Single-level lumbar fusion in chronic discogenic low-back pain: psychological and emotional status as a predictor of outcome measured using the 36-item Short Form. J Neurosurg Spine 2005;3:255-61.

55. Lutz GK, Butzlaff ME, Atlas SJ, Keller RB, Singer DE, Deyo RA. The relation between expectations and outcomes in surgery for sciatica. J Gen Intern Med 1999;14:740-4.

56. McGregor AH, Hughes SP. The evaluation of the surgical management of nerve root compression in patients with low back pain: part 2: patient expectations and satisfaction. Spine (Phila Pa 1976) 2002;27:14716.

57. Toyone T, Tanaka T, Kato D, Kaneyama R, Otsuka M. Patients' expectations and satisfaction in lumbar spine surgery. Spine (Phila Pa 1976) 2005;30:2689-94.

58. Atlas SJ, Keller RB, Robson D, Deyo RA, Singer DE. Surgical and nonsurgical management of lumbar spinal stenosis: four-year outcomes from the
Maine Lumbar Spine Study. Spine (Phila Pa 1976) 2000;25:556-62.

59. Daltroy LH, Cats-Baril WL, Katz JN, Fossel AH, Liang $\mathrm{MH}$. The North American Spine Society lumbar spine outcome assessment instrument: reliability and validity tests. Spine (Phila Pa 1976) 1996;21:741-9.

60. Fritzell P, Knutsson B, Sanden B, Stromqvist B, Hagg O. Recurrent versus primary lumbar disc herniation surgery: patient-reported outcomes in the Swedish Spine Register Swespine. Clin Orthop Relat Res 2015;473:1978-84.

61. Heyrani N, Picinic Norheim E, Elaine Ku Y, Nick Shamie A. Interspinous process implantation for the treatment of neurogenic intermittent claudication. Anesth Pain Med 2012;2:36-41.

62. Jagannathan J, Chankaew E, Urban P, et al. Cosmetic and functional outcomes following paramedian and anterolateral retroperitoneal access in anterior lumbar spine surgery. J Neurosurg Spine 2008;9:454-65.

63. Katz JN, Stucki G, Lipson SJ, Fossel AH, Grobler LJ, Weinstein JN. Predictors of surgical outcome in degenerative lumbar spinal stenosis. Spine (Phila $\mathrm{Pa}$ 1976) 1999;24:2229-33.

64. Knutsson B, Michaelsson K, Sanden B. Obesity is associated with inferior results after surgery for lumbar spinal stenosis: a study of 2633 patients from the Swedish Spine Register. Spine (Phila Pa 1976) 2013;38:435-41.

65. North RB, Ewend MG, Lawton MT, Kidd DH, Piantadosi S. Failed back surgery syndrome: 5-year follow-up after spinal cord stimulator implantation. Neurosurgery 1991;28:692-9.

66. Park DK, An HS, Lurie JD, et al. Does multilevel lumbar stenosis lead to poorer outcomes?: a subanalysis of the Spine Patient Outcomes Research Trial (SPORT) lumbar stenosis study. Spine (Phila Pa 1976) 2010;35:439-46.

67. Sanden B, Forsth P, Michaelsson K. Smokers show less improvement than nonsmokers two years after surgery for lumbar spinal stenosis: a study of 4555 patients from the Swedish Spine Register. Spine (Phila Pa 1976) 2011;36:1059-64.

68. Slosar PJ, Reynolds JB, Schofferman J, Goldthwaite N, White AH, Keaney D. Patient satisfaction after circumferential lumbar fusion. Spine (Phila Pa 1976) 2000;25:722-6.

69. BenDebba M, Heller J, Ducker TB, Eisinger JM. Cer- 
vical spine outcomes questionnaire: its development and psychometric properties. Spine (Phila Pa 1976) 2002;27:2116-23.

70. Johansson AC, Linton SJ, Bergkvist L, Nilsson O, Cornefjord M. Clinic-based training in comparison to home-based training after first-time lumbar disc surgery: a randomised controlled trial. Eur Spine J 2009;18:398-409.

71. Mannion AF, Mutter UM, Fekete FT, et al. The bothersomeness of patient self-rated "complications" reported 1 year after spine surgery. Eur Spine J 2012;21:1625-32.

72. Auerbach JD, Lenke LG, Bridwell KH, et al. Major complications and comparison between 3-column osteotomy techniques in 105 consecutive spinal deformity procedures. Spine (Phila Pa 1976) 2012;37:1198-210.

73. Kaptain GJ, Simmons NE, Replogle RE, Pobereskin L. Incidence and outcome of kyphotic deformity following laminectomy for cervical spondylotic myelopathy. J Neurosurg 2000;93(2 Suppl):199-204.

74. Kornblum MB, Fischgrund JS, Herkowitz HN, Abraham DA, Berkower DL, Ditkoff JS. Degenerative lumbar spondylolisthesis with spinal stenosis: a prospective long-term study comparing fusion and pseudarthrosis. Spine (Phila Pa 1976) 2004;29:72633.

75. Mannion AF, Fekete TF, O'Riordan D, et al. The assessment of complications after spine surgery: time for a paradigm shift? Spine J 2013;13:615-24.
76. Mannion AF, Porchet F, Kleinstuck FS, et al. The quality of spine surgery from the patient's perspective: part 1: the Core Outcome Measures Index in clinical practice. Eur Spine J 2009;18 Suppl 3:367-73.

77. Ohnmeiss DD, Bodemer W, Zigler JE. Effect of adverse events on low back surgery outcome: twentyfour-month follow-up results from a Food and Drug Administration investigational device exemptiontrial. Spine (Phila Pa 1976) 2010;35:835-8.

78. Porchet F, Lattig F, Grob D, et al. Comparison of patient and surgeon ratings of outcome 12 months after spine surgery: presented at the 2009 Joint Spine Section Meeting. J Neurosurg Spine 2010;12:447-55.

79. Schiffman M, Brau SA, Henderson R, Gimmestad G. Bilateral implantation of low-profile interbody fusion cages: subsidence, lordosis, and fusion analysis. Spine J 2003;3:377-87.

80. Kjellby-Wendt G, Styf J. Early active training after lumbar discectomy: a prospective, randomized, and controlled study. Spine (Phila Pa 1976) 1998;23:234551.

81. Lorish TR, Tanabe CT, Waller FT, London MR, Lansky DJ. Correlation between health outcome and length of hospital stay in lumbar microdiscectomy. Spine (Phila Pa 1976) 1998;23:2195-200.

82. Aharony L, Strasser S. Patient satisfaction: what we know about and what we still need to explore. Med Care Rev 1993;50:49-79.

83. Carr-Hill RA. The measurement of patient satisfaction. J Public Health Med 1992;14:236-49. 